
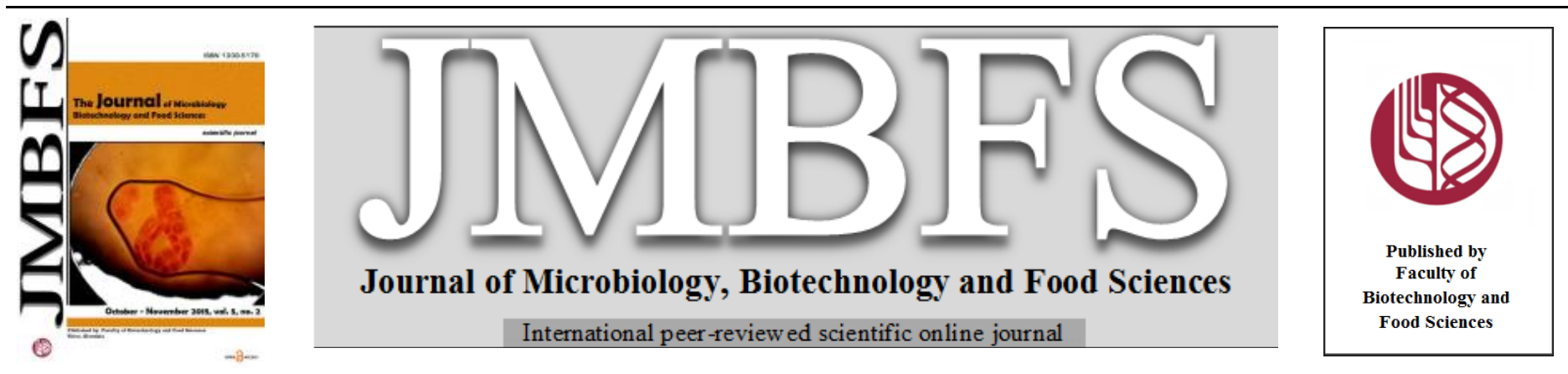

\title{
PRELIMINARY STUDIES OF BENZOTHIAZOLE AND BENZOTRIAZOLE MICROBIOLOGICAL DEGRADATION BY ACTIVATED SLUDGE ISOLATES
}

\section{Aleksandra Ziembińska-Buczyńska*, Klaudia Miczka, Katarzyna Kowalska, Ewa Felis}

\section{Address(es):}

The Silesian University of Technology, Environmental Biotechnology Department, The Faculty of Environmental Engineering and Power, Akademicka 2, 44-100 Gliwice, Poland.

*Corresponding author: Aleksandra.ziembinska-buczynska@polsl.pl

doi: 10.15414/jmbfs.2015.5.2.127-131

\section{ARTICLE INFO}

Received 22. 12. 2014

Revised 9. 6. 2015

Accepted 23. 6. 2015

Published 1. 10. 2015

Regular article

OPEN 2 ACCESS

\begin{abstract}
Benzothiazoles (BTs) and benzotriazoles (BTAs) are aromatic heterocyclic compounds which have been detected in aquatic environment, soil and wastewater treatment plants. These compounds demonstrate toxicity towards activated sludge microorganisms, as well as towards higher organisms, thus they are regarded as a threat to biological wastewater treatment. Studies performed on activated sludge as a mixed culture show that the transformation of BTs and BTAs is possible, in some cases also biologically. In this experiment it was revealed that BTA is degraded more easily and more efficiently than BT by activated sludge isolates. The decrease in the concentration of these compounds was not drastic but none of the isolated cultures were enriched or prepared to such a process performance. As a confirmation of these studies the next step in the analysis should be the culture pre-treatment (such as enrichment) or cometabolic degradation together with a more easily degradable carbon source.
\end{abstract}

Keywords: Activated sludge bacteria, benzothiazole, benzotriazole, biodegradation

\section{INTRODUCTION}

Benzothiazoles (BTs) and benzotriazoles (BTAs) are aromatic heterocyclic compounds which have been detected in aquatic environment and soil especially in urban areas and industrial areas, usually as micropollutants. Their presence in the environment likely originates from various industry branches (e.g. food, chemical, metallurgical or electrical industry), households and surface runoff from industrial areas.

Benzothiazoles (BTs) demonstrate toxicity towards activated sludge microorganisms, as well as towards the higher organisms. These compounds can be absorbed on the cell membrane surface of activated sludge microorganisms, which leads to their bioaccumulation and a decrease in wastewater treatment efficiency (Valdés and Zaror, 2006). Benzothiazoles and their derivatives are able to inhibit microorganisms' respiration and nitrification (Reemtsma et al., 1995).

Benzotriazoles are considerably soluble in water, their stability and resistance to biodegradation and limited sorption are the cause of their occurrence in the environment in significant quantity (surface water, such as rivers and lakes, and soils), where they may persist for long periods of time (Giger et al., 2006; Voutsa et al., 2006). BTs and BTAs are a serious problem in the environment mainly due to the ever increasing restrictions in the field of water quality regulations and the fact that these compounds biodegrade poorly.

Despite the negative impact of BTs and BTAs against activated sludge microorganisms, there is research indicating that biotransformation of these compounds is possible. Till now, microorganisms capable of BT biodegradation are shown to be Rhodococcus strain PA, Rhodococcus OBT18, Rhodococcus erythropolis strain $\mathrm{BTSO}_{3} 1$, Rhodococcus rhodochrous (immobilized) and Pseudomonas putida strain HKT 554 (De Wever et al., 1997; Chorao et al., 2009). In the case of benzothiazoles, their biodegradability depends on the type of substituent. De Wever $\boldsymbol{e t}$ al. (2001) identified a microorganism capable of 2hydroxybenzothiazole (OBT), 2-aminobenzothiazole (ABT) and benzothiazol-2sulfonate $\left(\mathrm{BTSO}_{3}\right)$ degradation, while information about 2merkaptobenzothiazole (MBT) biodegradation was ambiguous.

The results of Gaja and Knapp (1998) show that both strains of Rhodococcus (PA and OBT18) are capable of BT and OBT degradation, though they are not able to degrade 2 - mercaptobenzothiazole (MBT). Moreover, Rhodococcus erythropolis strain $\mathrm{BTSO}_{3} 1$ is also capable of $\mathrm{BTSO}_{3}$ degradation (De Wever et al., 1997). The pathways for $\mathrm{BT}, \mathrm{OBT}$ and $\mathrm{BTSO}_{3}$ transformation are probably connected. The biotransformation process of BTs in aerobic condition was described by De Wever et al. (1998). According to these results, $\mathrm{BT}$ and $\mathrm{BTSO}_{3}$ possess an intermediate product (OBT), which is hydroxylated in the next step to diOBT. This transformation scheme is presented in figure 1.<smiles>O=S(=O)(O)c1nc2ccccc2s1</smiles><smiles>Cc1nc2c(Br)c(O)ccc2s1</smiles>

Figure 1 Biotransformation of BTs by Rhodococcus erythropolis $\mathrm{BTSO}_{3} 1$ (De Wever et al., 1998)

Haroune et al. (2002) described the pathway for BT biotransformation by Rhodococcus pyridinovorans strain PA. At the beginning of the process, there were observed the same stages (till the formation of diOBT), which are probably catalyzes by monooxygenases. Next, diOBT is transformed to catechol, which is converted to dicarboxylic acid by catechol 1,2-dioxygenase.

Initially, it was thought that 2 - mercaptobenzothiazole is not capable of biotransformation and cannot be a source of carbon, nitrogen and energy for Rhodococcus strain PA (Gaja and Knapp, 1997). Results of De Wever et al. (1998) show that the simultaneous biodegradation of MBT, BT, OBT and 
BTSO3 by Rhodococcus erythropolis strain BTSO3 is not possible. It was hypothesized that MBT and its metabolites inhibit activity enzymes necessary for BT degradation. However, the results of El-Bassi et al. (2010) show that MBT biotransformation by Pseudomonas putida (strain HKT 554) is possible. These microorganisms are capable of MBT transformation to 2 methylthiobenzothiazole (MTBT) in the presence of naphthalene dioxygenase. Studies performed on activated sludge as a mixed culture show that BTA transformation is possible in both aerobic and anaerobic conditions, but the intermediate products are different (Liu et al., 2012). In aerobic conditions 1methylbenzotriazol, phthalic acid, 4-methoxybenzotriazol and 5methoxybenzotriazol were formed. While under anaerobic conditions 1 methylbenzotriazole, $\mathrm{N}, \mathrm{N}$ - dimethylaniline and carbazole were produced. It is important to underline that all intermediate products were next transformed to phenol. Thus, it became clear that an eco-friendly method for removing these compounds from the environment is necessary and the biological methods for their biotransformation and removal seem to be promising tools.

The presence of benzotriazole in WWTP has been stated in two Polish wastewater treatment plants - in Zabrze (Southern Poland) and Gdańsk (Northern Poland) in concentration of $0.5-1.7 \mu \mathrm{g} . \mathrm{L}^{-1}$ and $1.2-3.3 \mu \mathrm{g} . \mathrm{L}^{-1}$, respectively, while removal rate of this compound was $26-73 \%$ (Felis et al., 2012) Relatively high concentrations of these compounds indicate that a large portion of activated sludge bacteria are resistant towards benzotriazoles and it is possible that some of them can also be involved in their removal. That is why the aim of this study was to isolate banzotriazole and benzothiazole resistant bacteria from the activated sludge collected from the communal WWTP in Zabrze, Poland and to test them for BT and BTA biodegradation.

\section{MATERIALS AND METHODS}

\section{Benzotriazole and benzothiazole resistant bacteria enumeration}

Bacteria able to grow on media containing benzotriazole and benzothiazole were isolated from activated sludge samples obtained from the communal wastewater treatment plant in Zabrze, Poland. Samples were collected twice, in July and September 2012 and they were kept in $4^{\circ} \mathrm{C}$ till further analysis.

In order to estimate the total bacterial number in the activated sludge samples, Mueller-Hinton solid medium was used (BTL, Lodz, Poland; containing 17.5 g.L ${ }^{1}$ peptone KA, 2 g. $\mathrm{L}^{-1}$ meat extract, 1.5 g.. $\mathrm{L}^{-1}$ starch and $17 \mathrm{~g} . \mathrm{L}^{-1}, \mathrm{pH}=7.3$ ). The activated sludge samples were diluted to $10^{-10}$ in sterile $0.85 \% \mathrm{NaCl}$ solution and inoculated on Petri dishes in triplicate. The samples were incubated for 48 hours at $25 \pm 2{ }^{\circ} \mathrm{C}$. After the incubation bacteria were uncounted.

To estimate the number of benzothiazole (BT) and benzotriazole (BTA) resistant bacteria in the activated sludge samples, Mueller-Hinton solid medium was used, which contains separately: benzotriazole (97\%, Sigma-Aldrich) and benzothiazole $\left(96 \%\right.$, Sigma-Aldrich) in the final concentration of $20 \mathrm{mg} \cdot \mathrm{L}^{-1}$. BT and BTA were spread over the Petri dishes with Mueller-Hinton medium 30 minutes before inoculation. The samples were incubated for 48 hours in $25 \pm$ $2{ }^{\circ} \mathrm{C}$. The inoculation was performed in triplicate. After incubation bacteria remained uncounted. The same procedure was used for estimating the number of bacteria potentially degrading benzothiazole and benzotriazole. In this case Kojim solid mineral medium was used $\left(3.78\right.$ g.L $\mathrm{L}^{-1} \mathrm{Na}_{2} \mathrm{HPO}_{4} \times 12 \mathrm{H}_{2} \mathrm{O}, 0.5$ g.L $\mathrm{KH}_{2} \mathrm{PO}_{4}, 5$ g.L $\mathrm{L}^{-1} \mathrm{NH}_{4} \mathrm{Cl}, 0.2$ g.L $\mathrm{L}^{-1} \mathrm{MgSO}_{4} \times 7 \mathrm{H}_{2} \mathrm{O}, 0.01$ g.L $\mathrm{L}^{-1}$ yeast extract, 20 g. $\mathrm{L}^{-1}$ agar, $\mathrm{pH}=7.2$ ).

\section{Pure strains isolation and identification}

Bacterial colonies differing in morphology were collected from Kojim solid medium and purified at agar broth plates $\left(2.0\right.$ g.L $\mathrm{L}^{-1}$ meat extract, $8.0 \mathrm{~g}$.. $\mathrm{L}^{-1}$ peptone, 5.0 g.L $\mathrm{L}^{-1} \mathrm{NaCl}, 15 \mathrm{~g} . \mathrm{L}^{-1}$ agar; BTL, Lodz, Poland). After purification bacteria were kept frozen as the suspension in $98 \%$ glycerol (in proportion 1:1 $\mathrm{v} / \mathrm{v})$ at $-45^{\circ} \mathrm{C}$. In order to characterize the pure strains morphologically, Gram staining was performed and the genetic identification was undertaken.

A 24 hour culture in a broth medium was centrifuged, suspended in $100 \mu \mathrm{l}$ Tris buffer and the total bacterial DNA was isolated from the bacterial cells using a Genomic Mini Spin Kit (A\&A Biotechnology). On the basis of the DNA isolated for pure strains, PCR amplification with $8 \mathrm{~F}$ (5' GTG CTG CAG AGA GTT TGA TCC TGC TCA G 3') and 536R (5' CAC GGA TCC GTA TTA CCG CG 3') primers were performed (Schlesinger et al., 2005). PCR was performed in a total volume of $30 \mu \mathrm{l}$ in a mixture consisting of: $1 \times$ buffer (Promega), $2 \mathrm{mM} \mathrm{MgCl}$ (Promega), 5 pM. $\mu \mathrm{L}^{-1}$ of each $8 \mathrm{~F} / 536 \mathrm{R}$ primers (Genomed), $20 \mathrm{pM} . \mu \mathrm{L}^{-1} \mathrm{dNTPs}$ and 1.5 U GoTAQ Flexi (Promega). DNA in concentration of $0.15-0.2 \mu \mathrm{g} \cdot \mu \mathrm{L}^{-1}$ was added as a template. Amplification was performed in $\mathrm{C}-1000$ Thermocycler (BioRad) according to the temperature profile: $95^{\circ} \mathrm{C} / 5 \mathrm{~min}, 95^{\circ} \mathrm{C} / 45 \mathrm{~s}, 54^{\circ} \mathrm{C} / 45 \mathrm{~s}$, $72^{\circ} \mathrm{C} / 45 \mathrm{~s}$ ( 30 cycles), $72^{\circ} \mathrm{C} / 5 \mathrm{~min}$. PCR product was evaluated in $1 \%$ agarose gel (w/v) according to standard procedure. PCR products were purified with a Clean Up Kit (A\&A Biotechnology), reamplified and sequenced with BigDye ${ }^{\mathbb{B}}$ Terminator v3.1 kit (Applied Biosystems). DNA Analyzer Sequences were aligned in BLAST (Basic Local Alignment Search Tool) and compared with GenBank NCBI (National Center for Biotechnology Information).

\section{Benzothiazole and benzotriazole biodegradation possibility assessment}

In order to estimate the possibilities and/or efficacy of benzothiazole and benzotriazole biodegradation with bacteria isolated from activated sludge, the microorganisms growing on Kojim solid mineral medium were washed to $100 \mathrm{~m}$ of sterile liquid Kojim medium containing respectively, BT and BTA (20 mg.L $\left.{ }^{1}\right)$. $\mathrm{OD}_{600 \mathrm{~nm}}$ value was measured in the beginning of the experiment and after every 24 hours using 8452A Diode Array Spectophotometer (Hewlett Packard). Strains in liquid medium were incubated for 5 days at $25^{\circ} \mathrm{C}$ with $125 \mathrm{rpm}$ shaking.

\section{HPLC analysis}

In order to analyze the benzotriazole and benzothiazole concentration changes the samples, which were collected every 24 hours, were filtered (Whatman ${ }^{\circledR}$ Cellulose Nitrate Membrane Filters 0,2 $\mu \mathrm{m} \varnothing 25 \mathrm{~mm}$ ), and analyzed with RP HPLC - Reverse Phase High Performance Liquid Chromatography (Chromatograph UMate 3000; Dionex) coupled with UV-VIS detector. Detection was performed at four wavelengths: $210 \mathrm{~nm}, 220 \mathrm{~nm}, 262 \mathrm{~nm}, 278 \mathrm{~nm}$ for benzotriazole and $218 \mathrm{~nm}, 254 \mathrm{~nm}, 284 \mathrm{~nm}, 294 \mathrm{~nm}$ for benzothiazole. The solid phase was Hypersil GOLD (RP-C18) chromatographic column (TermoElectron Corporation) and the liquid phase was a mixture of acetonitryle and water in a volumetric ratio of $60: 40(\mathrm{v} / \mathrm{v})$. The analyses were performed at the isocratic flow mode. The flow rate of the eluents through the chromatographic column was equal to $1 \mathrm{~mL} \cdot \mathrm{min}^{-1}$. In the above-described conditions, the retention times (RT) of benzotriazole and benzothiazole were equal to $2.18 \pm 0.20 \mathrm{~min}$ and $3.00 \pm 0.20 \mathrm{~min}$, respectively.

\section{RESULTS}

Enumeration of benzotriazole and benzothiazole resistant and potentially degrading bacteria in activated sludge

The total bacterial number isolated from activated sludge derived from the communal wastewater treatment plant in Zabrze, Poland was estimated on Mueller-Hinton solid medium and calculated at level of $10.4 \times 10^{9} \mathrm{CFU}_{\mathrm{mL}}{ }^{-1}$. The number of BT and BTA resistant bacteria was enumerated on the same solid medium with the addition of BT, BTA and BTA/BT at a concentration of 20 mg. $\mathrm{L}^{-1}$ each. The number of bacteria potentially able to biodegrade BT and BTA was estimated on mineral Kojim medium. Figure 2 presents a comparison of bacteria resistant towards BT and BTA and potentially able to biodegrade these compounds.

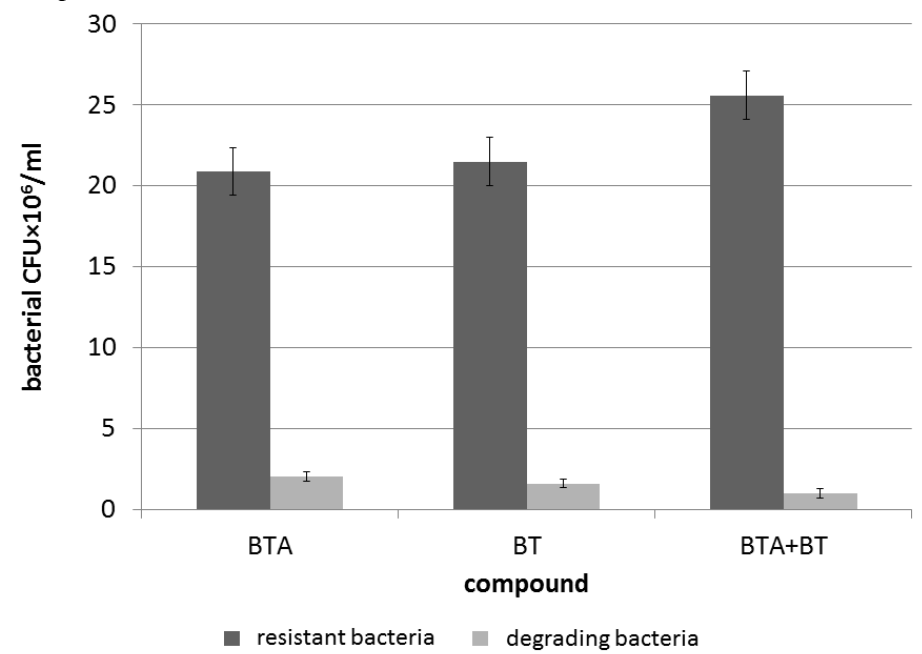

Figure 2 The comparison of the number of bacteria resistant towards BT and BTA (on Mueller-Hinton medium with the addition of BT and BTA in final concentration of $20 \mathrm{mg} . \mathrm{L}^{-1}$ ) and potentially able to biodegrade these compounds (on Kojim medium with the addition of BT and BTA in final concentration of 20 mg. $\mathrm{L}^{-1}$; BTA - benoztriazole, BT - benzothiazole)

\section{Morphological characterization and identification of isolated BT and BTA resistant bacteria}

From the Mueller-Hinton medium several BT and BTA strains were isolated for further research. They differ in their macroscopic and microscopic morphology as presented in Table 1 . The PCR products of the partial 16S rRNA coding gene underwent DNA sequencing and the results were compared with the NCBI GenBank. Table 2 presents the results of strains the most possible identification. The DNA sequencing results obtained for strains TR3 and T4 were not clear, thus we suspect that these strains were mixed cultures. 
Table 1 Morphological characteristic of isolated strains

\begin{tabular}{|c|c|c|c|c|}
\hline Compound & Strain & Gram stain & $\begin{array}{l}\text { Cell } \\
\text { morphology }\end{array}$ & Collony morphology \\
\hline \multirow{4}{*}{ Benzotriazole resistant bacteria } & TR1 & $\mathrm{G}(+)$ & cocci & yellow, small \\
\hline & TR2 & $\mathrm{G}(-)$ & cocci & white, small \\
\hline & TR3 & $G(-)$ & cocci & yellow, small \\
\hline & TR4 & $\mathrm{G}(-)$ & cocci & yellow, small \\
\hline \multirow{4}{*}{ Benzothiazole resistant bacteria } & $\mathbf{T 1}$ & $\mathrm{G}(+)$ & rod-shaped & white, large, diffuse, fast growing \\
\hline & $\mathbf{T 2}$ & $\mathrm{G}(-)$ & cocci & white, large, diffuse, fast growing \\
\hline & $\mathbf{T 3}$ & $\mathrm{G}(-)$ & cocci & white, large, diffuse, fast growing \\
\hline & T4 & $\mathrm{G}(-)$ & cocci & white, large, diffuse, fast growing \\
\hline \multirow{2}{*}{$\begin{array}{l}\text { Benzothiazole/benzo-triazole } \\
\text { resistant bacteria }\end{array}$} & TR+T1 & $\mathrm{G}(-)$ & cocci & light yellow, slow growing \\
\hline & $\mathbf{T R}+\mathbf{T} 2$ & $\mathrm{G}(-)$ & cocci & light yellow, fast growing \\
\hline
\end{tabular}

Table 2 Genetic identification of the isolated strains according to NCBI GenBank

\begin{tabular}{llcc}
\hline Strain & Identification & Similarity [\%] & NCBI accesion number \\
\hline TR1 & Acinetobacter sp. B43(2011) 16S ribosomal RNA gene, partial sequence & $99 \%$ & JN228293.1 \\
\hline TR2 & $\begin{array}{l}\text { Uncultured proteobacterium clone MS068A1_C11 16S ribosomal RNA gene, } \\
\text { partial sequence }\end{array}$ & $99 \%$ & $\underline{\text { EF702439.1 }}$ \\
\hline TR3 & Bacillus subtilis strain F41 16S ribosomal RNA gene, partial sequence* & $96 \%$ & $\underline{\text { GU998816.1 }}$ \\
\hline TR4 & MicrobacteriumW5(2005) 16S ribosomal RNA gene, partial sequence & $96 \%$ & DQ191237.1 \\
\hline T1 & $\begin{array}{l}\text { Uncultured proteobacterium clone MS068A1_C11 16S ribosomal RNA gene, } \\
\text { partial sequence }\end{array}$ & $97 \%$ & EF702439.1 \\
\hline T2 & Bacillus cereus strain N419 16S ribosomal RNA gene, partial sequence & $100 \%$ & $\underline{\text { JN400121.1 }}$ \\
\hline T3 & Acinetobacter sp. HM_AF14 16S ribosomal RNA gene, partial sequence & $99 \%$ & JN573359.1 \\
\hline T4 & $\begin{array}{l}\text { Uncultured bacterium clone ncd2494g12c1 16S ribosomal RNA gene, partial } \\
\text { sequence* }\end{array}$ & $96 \%$ & $\underline{\text { JF215243.1 }}$ \\
\hline TR1+T1 & Acinetobacter sp. CIP 102129 16S ribosomal RNA gene, partial sequence & $99 \%$ & JQ638576.1 \\
\hline TR2+T2 & Uncultured bacterium clone C2 16S ribosomal RNA gene, partial sequence & $98 \%$ & $\underline{\text { HQ852983.1 }}$ \\
\hline *Sequencing results not clear - probably mixed culture & &
\end{tabular}

\section{Biodegradation experiment for isolated strains}

The strains isolated in this experiment were grown on liquid Kojim medium with the addition of $20 \mathrm{mg} \cdot \mathrm{L}^{-1}$ of BT and BTA in order to estimate their potential for the biodegradation of these compounds. The concentration of BT and BTA in the medium during the experiment was analyzed with HPLC. To estimate bacterial growth, $\mathrm{OD}_{600 \mathrm{~mm}}$ was measured. The results for benzotriazole degrading bacteria are presented in figure 3 , for benzothiazole degrading bacteria in figure 4 and for benzotriazole/banzothiazole degrading bacteria in figure 5 .
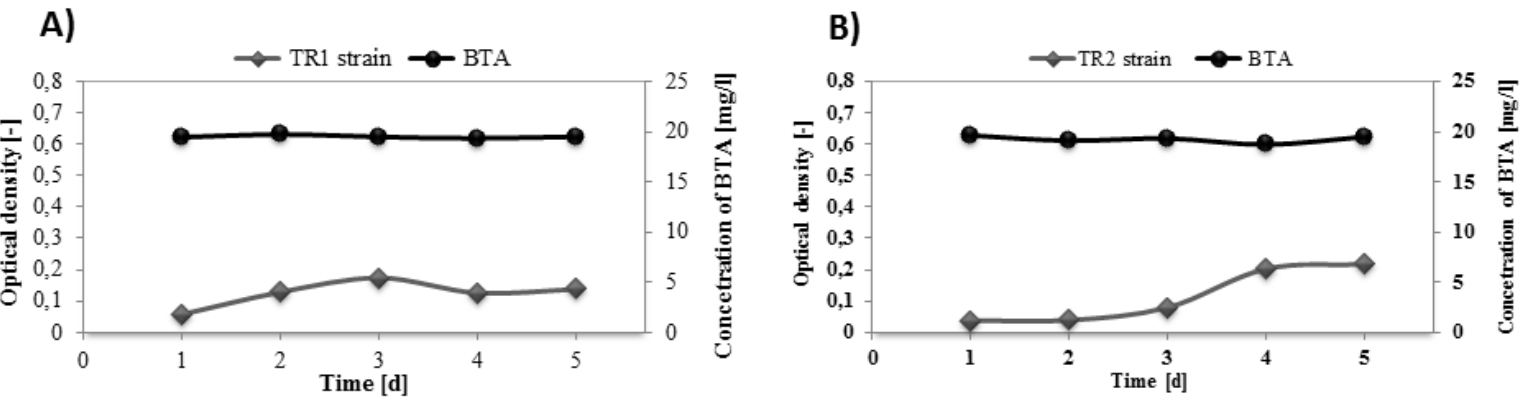

C)

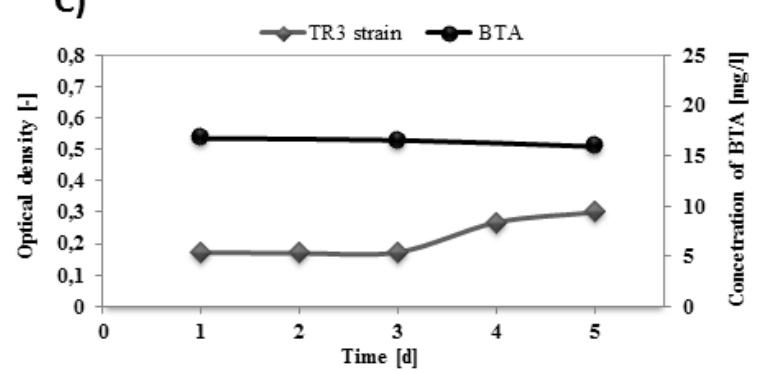

D)

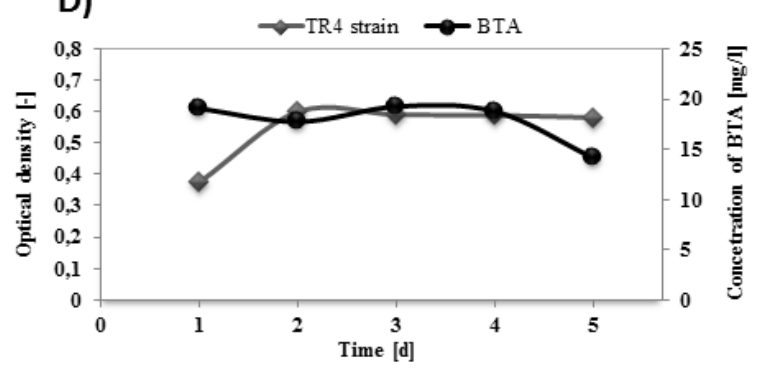

Figure 3 Benzotriazole (BTA) concentration changes and optical density of strains: A) TR1, B) TR2, C) TR3, D) TR4 cultured in liquid Kojim medium 
A)

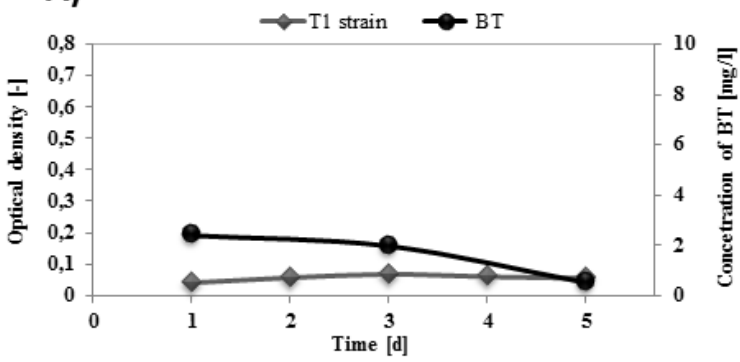

C)

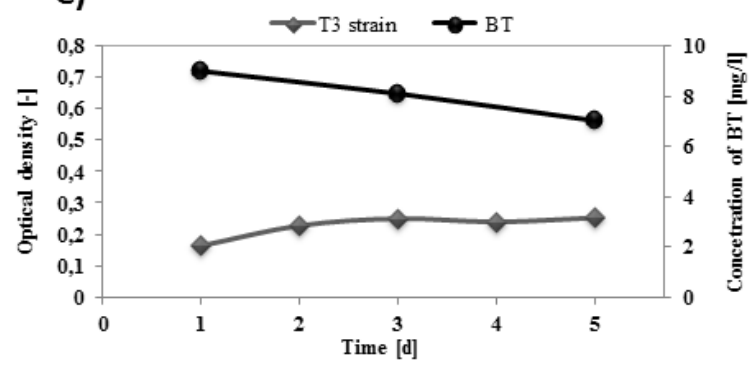

B)

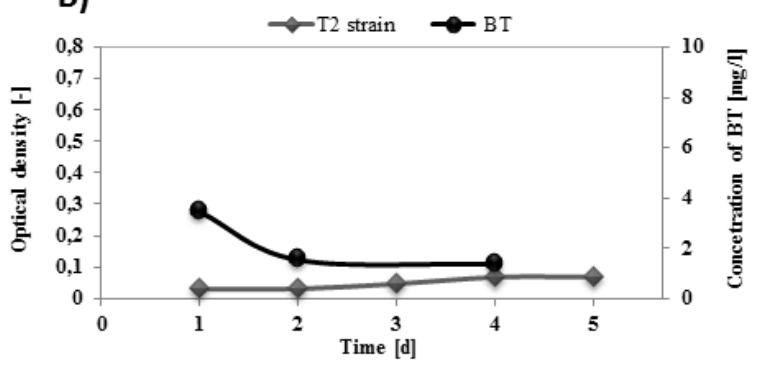

D)

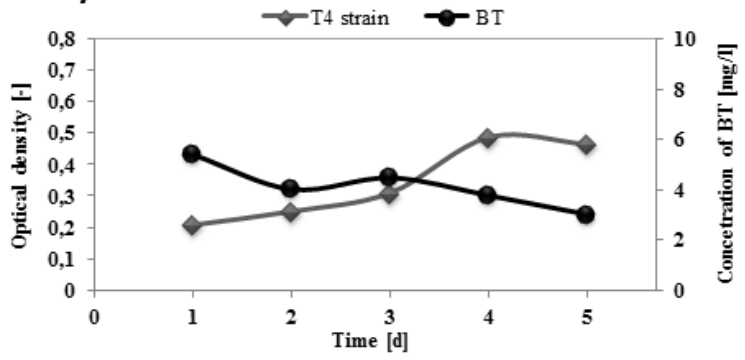

Figure 4 Benzothiazole (BT) concentration changes and optical density of strains: A) T1, B) T2, C) T3, D) T4 cultured in liquid Kojim medium

A)

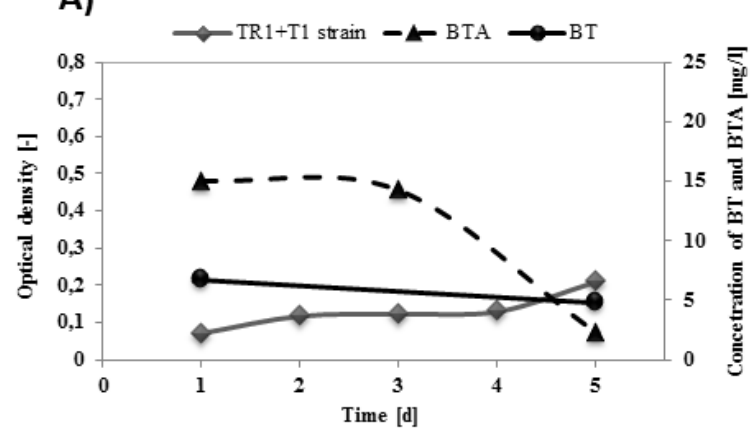

B)

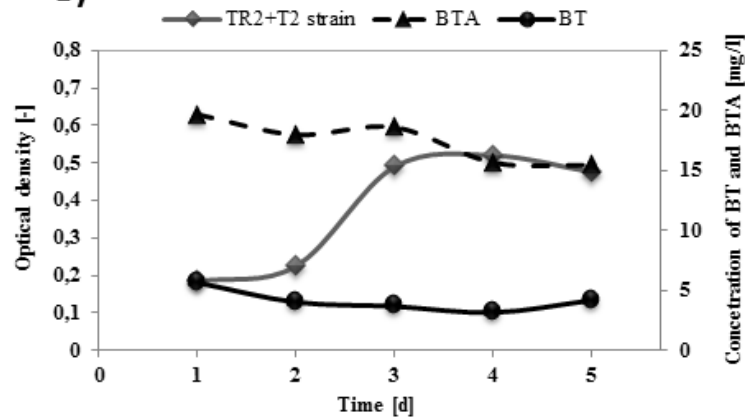

Figure 5 Benzothiazole (BT) and benziotriazole (BTA) concentration changes and optical density of strains: A) TR1+T1, B) TR2+T2 cultured in liquid Kojim medium

\section{DISCUSSION}

Benzotriazoles and benzothiazoles are xenobiotics present in the environment and potentially harmful to organisms. Moreover, biological wastewater treatmen plants are not able to remove these compounds efficiently from sewage. In this experiment we used high concentrations of these compounds $\left(20 \mathrm{mg} . \mathrm{L}^{-1}\right)$ due to the fact that they can be present in the environment also in high concentrations. We estimated the number of BT and/or BTA bacteria resistant and potentially able to biodegrade these compounds. In this way we could present the resistance potential of particular bacteria, not the activated sludge as a whole, because sludge can buffer the harmful effect of the lower concentrations of recalcitrant. Needless to say, these estimations of bacteria number on microbiological media should be considered as an approximate result, because there is no universal medium and optimal laboratory conditions for all bacteria and more than $99 \%$ of environmental microorganisms are uncultivable. Thus these results consider only the bacteria growing on a particular type of medium under laboratory conditions. As it can be seen in figure 2 the number of bacteria with potential for BT and BTA biodegradation is far lower $\left(1-2 \mathrm{CFU} \times 10^{6} . \mathrm{mL}^{-1}\right)$ than bacteria resistant towards these compounds $\left(20.9-25.6 \mathrm{CFU} \times 106 . \mathrm{mL}^{-1}\right)$. These results suggest that a large amount of activated sludge bacteria can buffer the harmful BT and BTA effect, while only a small proportion of them are able to transform these compounds.

The strains isolated on solid media, resistant and potentially degrading BT, were characterized morphologically and genetically on the basis of a partial $16 \mathrm{~S}$ rRNA coding gene.

Under microscopic observation all but TR1 and T1 strains were Gram-negative and all but T1 (rod-shaped bacterium) were cocci. Their partial 16S rRNA coding gene underwent sequencing and enabled the identification of these bacteria by comparing their DNA with the NCBI database (table 2). It should be mentioned that in this case the identification cannot be precise to the level of species because it was performed only on a $500 \mathrm{bp}$ gene fragment. Only with strain T2 did we obtain $100 \%$ alignment of the sequence for Bacillus cereus (accession no.
JN400121.1). Strains TR1, T3 and TR1+T1 with 99\% precision were classified as Acinetobacter, strain TR3 (96\%) - Bacillus, and TR4 (96\%) Microbacterium. Strains TR2, T1, T4 and TR2+T2 belong to the uncultured microorganisms, probably the largest environmental group of bacteria able to degrade xenobiotics.

As it can be seen in tables 1 and 2, the results from the classical morphological approach differ from the DNA-based identification. All identified genera: Acinetobacter, Bacillus, Microbacterium are known to be rod-shaped bacteria. But in the case of this experiment only T1 strain is rod-shaped, and it was not identifiable as a particular genus. Also, Gram staining differs for strain TR1 (Acinetobacter) - Gram-positive and strains TR3, T2 (Bacillus) and TR4 (Microbacterium) - Gram-negative which is not typical for them.

Nonetheless, it is possible that these strains belong to the Gram-variable (or Gram-indetermine) bacteria, as it is possible, especially for Gram-positive bacteria (i.e. Bacillus). This could also appear in the case of older bacteria cultures or a lack in the medium of compounds for cell wall production. Some bacteria can be pleomorphic, they can change shape under physical or chemical pressure in environmental conditions. They could also be present in the case of nutrient shortages. In this case the harmful (toxic) effect of BT and BTA could be the very cause of such results for Gram staining and the morphological observations.

Isolated strains were able to grow on solid Kojim mineral medium with BT and/or BTA as a sole carbon source. These results point to their potential ability to biodegrade these compounds. However, a possibility exists that bacteria growing on the Kojim medium are only resistant towards BT and/or BTA and that their growth is a result of the previously accumulated reserve substances of easily degradable EPS. To verify this hypothesis we performed biodegradation cultures on a liquid Kojim medium with BT and BTA in a concentration of 20 mg. $\mathrm{L}^{-1}$. During this experiment all isolated strains were resistant towards BT and/or BTA and their biomass increased.

Strains TR1 and TR2 did not present any degradation abilities towards BTA (figure $3 \mathrm{a}, \mathrm{b}$ ). The bacteria growth on a mineral medium can suggest that they 
possess a higher level of reserve substances with no usage of BTA as a carbon source. Their growth on the mineral medium can suggest that they possess more reserve substances or they could produce cell envelopes or EPS as a nutritional reserve.

A slight decrease in BTA concentration was observed for strain TR3, which correlates with its optical density increase (figure $3 \mathrm{c}$ ). It could indicate that the bacteria adapted to this compound degradation but it is highly improbable that TR3 is able to degrade BTA.

In strain TR4 (figure 3d), during the last day of the experiment, BTA concentration decreased significantly (to $14.12 \mathrm{mg} . \mathrm{L}^{-1}$ ), but there was no correlation with a $\mathrm{OD}_{600}$ increase (after a sudden optical density increase in the beginning of the experiment it was relatively constant). Such results could suggest that this strain was highly resistant towards BTA and it could grow efficiently in the presence of this compound. It could be also possible that the strain possessed enough reserve substances adequate to survive until the enzymes enabling BTA degradation were turned on.

It is important to note that in the case of BT cultures, the initial concentration of the compound were lower than originally added (from $2.39 \mathrm{mg} . \mathrm{L}^{-1}$ for strain $\mathrm{T} 1$ to $8.99 \mathrm{mg} . \mathrm{L}^{-1}$ for T3). BT sorption on glass surfaces and microorganisms was excluded. Thus, we assumed that the cause for this situation was BT low water solubility, which is 4.3 g. $\mathrm{L}^{-1}$ in $25^{\circ} \mathrm{C}$, but no information is available as to the solubility properties at any other temperatures. It is suspected that BT solubility at lower temperatures is far lower. The BT standard solution which was added to the Kojim medium was kept in $4^{\circ} \mathrm{C}$, but the samples were collected from liquid media and frozen in $-45^{\circ} \mathrm{C}$. It is possible that the $\mathrm{BT}$ solution was removed from the samples during filtration or the initial concentrations were lower than expected. That is why this part of the experiment results is difficult to summarize. In strain T1, concentration of BT dropped (figure 4a), but its optical density was unchanged. The lack of growth can suggest that either the BT concentration is toxic to some part of the inoculum (only those with reserve substances can survive), or it is a substrate with insufficient energy to enable cell growth.

In the case of strain T2, BT concentration dropped (figure 4b), which indicates its possible degradation. The highest decrease in its concentration was in the second day of the experiment. Together with a BT concentration decrease, a slow growth of bacteria is observed. Such a slow increase in the optical density can indicate the toxic influence of the compound or too low a concentration to feed the whole culture.

An optical density increase was observed together with a BT concentration decrease for strain T3 (figure 4c). In this case biodegradation processes cannot be excluded but confirmation requires further research.

Strain T4 presented the highest increase in optical density (the most visible in the $4^{\text {th }}$ day of the experiment; figure 4d) together with a BT concentration decrease. In this case it is also suspected that the strain could possess biodegradation potential towards BT.

On the basis of these results BT is suspected to be more toxic and difficult to degrade than BTA. Difficulty also arose when preparing liquid media with a constant BT concentration for culture start up. In each case of BT-degrading cultures, the optical density increase was very low while on agar plates they grew more efficiently.

Optical density for strain TR1+T1 increased slowly, with the highest level between $4^{\text {th }}$ and $5^{\text {th }}$ day of the experiment (figure $5 \mathrm{a}$ ). In the last day, the concentration of both compounds decreased (BTA faster and to a lower degree that BT). A similar situation was observed for strain TR2+T2 (figure 5b) with the highest $\mathrm{OD}_{600 \mathrm{~nm}}$ increase between the $2^{\text {nd }}$ and $3^{\text {rd }}$ day with a BT and BTA concentration decrease at the end of the experiment (as in the case of TR1+T1, the BTA concentration decreased more visibly than BT). These results lead us to think that the isolated strains TR1+T1 and TR2+T2 are able to degrade BTA more efficiently than BT. It is possible that degradation for both compounds utilizes the same metabolic pathways and the same enzymes, which is why BT is also degraded but more slowly and at a lower rate.

\section{CONCLUSION}

According to the results obtained during these studies, we can suspect that BT and BTA combined are easier to degrade than each compound separately. BTA is degraded more easily and more efficiently than BT. The decrease in the concentration of these compounds was not drastic but it is worth mentioning that none of the isolated cultures were enriched nor prepared for such process performance. As a confirmation of these studies and a next step in the analysis, the cultures should be pre-treated (BT and BTA enrichment to adapt the strains to a high compound concentration) and the cometabolic degradation should be prepared together with an easier to degrade carbon source.

\section{REFERENCES}

CHORAO, C., CHARMANTRAY, F., BESSE-HOGGAN, P., SANCELME, M., CINCILE, A., TRAÏKIA, M., MAILHOT, G. DELORT, A.M. 2009. 2 Aminobenzothiazole degradation by free and Ca-alginate immobilized cells of Rhodococcus rhodochrous. Chemosphere, 75, 121-128. http://dx.doi.org/10.1016/i.chemosphere.2008.11.021.
DE WEVER, H., BESSE, P. VERACHTERT, H. 2001. Microbial transformations of 2-substituted benzothiazoles. Applied Microbiology and Biotechnology, 57, 620-625.

DE WEVER, H., VAN DEN NESTE, S. VERACHTERT, H. 1997. Inhibitory effects of 2-Mercaptobenzothiazole on microbial growth in a variety of trophic conditions. Environmental Toxicology and Chemistry, 16, 843-848 http://dx.doi.org/10.1002/etc.5620160502.

DE WEVER, H., VEREECKEN, K., STOLZ, A. VERACHTERT H. 1998. Initial transformations in the biodegradation of benzothiazoles by Rhodococcus isolates. Applied and Environmental Microbiology, 64, 3270-3274.

EL-BASSI, L., IWASAKI, H., OKU, H., SHINZATO, N. MATSUI, T. 2010. Biotransformation of benzothiazole derivatives by the Pseudomonas putida strain HKT554.

Chemosphere,

81

109-113.

http://dx.doi.org/10.1016/j.chemosphere.2010.07.024.

FELIS, E., SURMACZ - GÓRSKA, J., ZIEMBIŃSKA, A. GNIDA, A. 2012 Fate of benzotriazole in wastewater treatment plants in Poland. In Ecotechnologies for Wastewater Treatment. Book of abstract of Ecotechnologies for Wastewater Treatment 2012, Santiago de Compostela, Spain. IWA International Conference, ISBN: 978-84-695-3605-6.

GAJA, M. A. KNAPP, J. S. 1998. Removal of 2-mercaptobenzothiazole by activated sludge: a cautionary note. Water Research, 32, 3786-3789. http://dx.doi.org/10.1016/S0043-1354(98)00146-8.

GAJA, M. A. KNAPP, J. S. 1997. The microbial degradation of benzothiazoles Journal of Applied Microbiology, 83, 327-334.

GIGER, W., SCHAFFNER, C. HANS-PETER, E. K. 2006. Benzotriazole and tolyltriazole as aquatic contaminants. 1. Input and occurrence in rivers and lakes. Environmental Scence and Technology, 40, 7186-7192. http://dx.doi.org/10.1021/es061565j.

HAROUNE, N., COMBOURIEU, B., BESSE, P., SANCELME, M. REEMTSMA, T., KLOEPFER A., DIAB A., KNAPP J. S.,BAUMBERG S. DELORT A. M. 2002. Benzothiazole degradation by Rhodococcus pyridinovorans strain PA: evidence of a catechol 1,2-dioxygenase activity Applied and Environmental Microbiology, 68, 6114-6120. http://dx.doi.org/10.1128/AEM.68.12.6114-6120.2002.

LIU, Y.S., YING, G.G., SHAREEF, A. KOOKANA, R. S. 2012. Biodegradation of three selected benzotriazoles under aerobic and anaerobic conditions. Water Research, 45, 5005-5014. http://dx.doi.org/10.1016/j.watres.2011.07.001

REEMTSMA, T., FIEHN, O., KALNOWSKI, G., JEKEL, M. 1995. Microbial transformations and biological effects of fungicide-derived Benzothiazoles determined in industrial wastewater. Environmental Science and Technology, 29, 478-485. http://dx.doi.org/10.1021/es00002a025.

SCHLESINGER, J., NAVON-VENEZIA, S., CHMELNITSKY, I., HAMMER MÜNZ, O., LEAVITT, A., GOLD, H.S., SCHWABER, M.J. CARMELI. Y. 2005. Extended-spectrum beta-lactamases among Enterobacter isolates obtained in Tel Aviv, Israel. Antimicrobial Agents and Chemotherapy, 45(49), 1150-56, 2005. http://dx.doi.org/10.1128/AAC.49.3.1150-1156.2005.

VALDÉS, H. ZAROR, C.A. 2006. Ozonation of benzothiazole saturatedactivated carbons: Influence of carbon chemical surface properties. Journal of Hazardous Materials, 137, 1042-1048 http://dx.doi.org/10.1016/j.jhazmat.2006.03.025.

VOUTSA, D., HARTMANN, P., SCHAFFNER, C. GIGER, W. 2006 Benzotriazoles, alkylphenols and bisphenol A in municipal wastewaters and in the Glatt River, Switzerland. Environmental Science and Pollution Research International, 13, 333-341 